\title{
12 Miles, 14 Years: A Critical Report on the Life Expectancy Gap between two N.J. Cities
}

\author{
Carolina Marques Borges ${ }^{1}$, Seana Cleary ${ }^{2}$, Deanna Amarosa ${ }^{3}$, Viane Villanueva ${ }^{4}$, Marina Celly Martins Ribeiro de Souza ${ }^{5^{*}}$ \\ ${ }^{1,5}$ Associate Professor, Department of Public Health, The College of New Jersey, USA. \\ ${ }^{2,3,4}$ Undergraduate Student, The College of New Jersey, USA.
}

\section{Article Details \\ Article Type: Research Article \\ Received date: $19^{\text {th }}$ September, 2019 \\ Accepted date: $16^{\text {th }}$ October, 2019 \\ Published date: $21^{\text {st }}$ October, 2019}

"Corresponding Author: Marina Celly Martins Ribeiro de Souza, Associate Professor, Department of Public Health, School of Nursing, Health and Exercise Science, The College of New Jersey, USA. E-mail. desouzam@tcnj.edu

Citation: Borges CM, Cleary S, Amarosa D, Villanueva V, De Souza MCMR (2019) 12 Miles, 14 Years: A critical report on the life expectancy gap between two N.J. cities. J Pub Health Issue Pract 3: 146. https://doi.org/10.33790/jphip1100146.

Copyright: $\mathbb{C} 2019$, This is an open-access article distributed under the terms of the Creative Commons Attribution License 4.0, which permits unrestricted use, distribution, and reproduction in any medium, provided the original author and source are credited.

\begin{abstract}
The U.S. is a well-developed country with some of the most innovative medical advancements in the world. However, health disparities still present a major public health challenge that manifests itself in residents who live just 12 miles apart, as seen in Trenton and Princeton, New Jersey. This critical report aimed to discuss life expectancy with a focus on the social determinants of health, contrasting the current panorama seen in Trenton and Princeton. This study has shown that the life-expectancy gap will continue to grow between these towns unless political action is taken. There cannot be a disconnect between the government and the community; it is necessary for government officials to listen to individual voices from the areas that they are impacting, whose lives depend on the actions they do or do not take. Any public policies implemented should be a collaboration between the public sector and private sector of Trenton in order to reach all consumers while still having the resources and funding available from the government to initiate the policies.
\end{abstract}

\section{Introduction}

The meaning of the word "causality" is rather ambiguous, and one person's definition may be entirely different from another's depending on what they were taught and how they view the world. Curious about how people's perspectives change as they age and experience more in life, we asked a sixth-grader, a college student, and a researcher what they thought of when we said the words "cause-and-effect." Each one of them believed it to mean that one factor leads to some final result: one cause, one effect, and nothing more. This prompted us to think about how over simplicity can affect society as a whole, specifically in regards to stereotyping. Take, for example, life expectancy. The World Health Organization [1] defines life expectancy as the average number of years someone born today is expected to live should current mortality rates persist. In 2015, the world's average life expectancy was approximately 71.9 years, ranging from 51 years in the Central African Republic and Sierra Leone to 84 years in Japan and various parts of China [2]. With great advances in medicine, science, and overall living conditions, including sanitation, education, and housing, it is assumed that America's life expectancy is increasing and that developing countries' life expectancies are remaining stagnant without these resources. One cause, one effect. Actually, the opposite is true. In 2016, U.S. life expectancy dropped 0.1 years from the previous year, [3] where as life expectancy in Africa has risen 6.6 years in the past decade. This rise is due in part to a drop in infant mortality of over $30 \%$ and better public health initiatives regarding the education on and treatment of HIV/AIDS [4], as well as increases in sectors like agriculture and mining [5]. But what initiated the change? Was it sudden or did it build up over time, stemming from many more small developments? Will life expectancy continue to climb, or will African countries see a decline similar to America's as other variables come into play? As topics unfold, layers and layers are revealed - what Drs. Michael Marmot and Ruth Bell term "the causes of the causes." [6] It is here, in these causes of causes, that steps can be taken to elicit a major change. So while a linear cause-and-effect relationship may be sufficient for general knowledge, fostering true understanding and empathy requires that cause-and-effect be thought of less like a line and more like a tree, with branches that overlap, intersect, and have no definite beginning or end.

The number of years a person is expected to live at birth cannot be attributed to a single agent or cause, but rather a plethora of social and physical determinants. Social determinants are conditions of the environment that surround a person in their everyday life. These include but are not limited to quality of and access to education, safety, social networks, healthcare, and socioeconomic stability. Physical determinants also affect health outcomes and include the natural and built environment, as well as physical barriers and hazards [7]. With these in mind, perhaps it is less complicated to understand how Sierra Leone and Japan have such a drastic life expectancy gap, with 33 years separating their respective life expectancies of 51 and 84 years [2].

Though the physical separation and resulting environments of each country can partly explain their life expectancy differences, a lesser known disparity exists on a far smaller scale and is much less easily explained. To some, twelve miles is merely the distance between a house and the nearest mall - a stretch of land rather monotonous and not particularly thought-provoking. To New Jerseyans, however, twelve miles can mean the difference of roughly fourteen years of life. The reasons behind this require a deeper look at New Jersey's capital, Trenton, and a historic landmark, Princeton, located twelve miles apart from each other in Mercer County. Trenton's life expectancy in 2016 was 73 years old while Princeton's was 87 years old, and enormous fourteen-year difference [8]. Additionally, NJSHAD [9] reported that in 2016, the average age at death for Trenton's residents 
was 64.3 years, while Princeton's residents lived an extra 18 years on average until their deaths at the age of 82.1 .

This critical report aimed to discuss life expectancy with a focus on the social determinants of health, contrasting the current panorama seen in Trenton, state Capital and Princeton as one of the wealthiest towns in New Jersey State.

\section{History}

The histories of the development of both Princeton and Trenton are integral contributors to the differences in life expectancy between the two cities. The economic and industrial decline of Trenton introduced poverty and financial struggle to the city. Without the major factories bringing in revenue and providing job opportunities for the residents of Trenton, the population now struggles to support itself financially. This means that areas like personal nutrition and education are not prioritized [10]. On the opposite end of the continuum, the Ivy League university located in Princeton draws educated, upper-class individuals to the town for the duration of their college experience, as well as world-renowned professors in every field. The relationship between the university and town has resulted in a joint financial effort to promote healthy lifestyles and attract profitable establishments to ensure its reputation for years to come [11].

In the $1800 \mathrm{~s}$, Trenton was at the peak of the Industrial Age - a premiere production city to support America's newfound growth and automation. At one point, it was ranked 50th among America's hundred largest cities. The city thrived in producing steel and pottery. It was home to one of the first steel mills in the United States of America. After the War of 1812, the mills that were present in Trenton transformed into larger industrial factories in order to support the demand for manufactured products. The city turned into a "diverse manufacturing center" that mainly focused on producing pottery, porcelain, iron, steel, and rubber. A strong immigrant labor force helped to support this industrialization of the city. In the 1930s, Trenton claimed the slogan "Trenton Makes, the World Takes," displaying it proudly on the Lower Trenton Bridge. Quite literally, this symbolizes the city's exceptional ability to provide goods and products for other American and global cities. Unfortunately, World War II facilitated a loss of control over the industries and introduced labor unrest and turmoil to the city. Ultimately, the factories were abandoned, sold, or destroyed, thus, marking the beginning of the post-industrial era that is currently present in Trenton. Lack of funding and violence has caused a decline in the support of the development of Trenton. The population in Trenton heavily suffered and continues to suffer due to the urban decay that occurred. This may be a big contributing factor to the lower life expectancy present in Trenton. The city's difficulty in trying to flourish and rebuild from the tragic economic and industrial decline has heavily affected the residents [10].

Princeton was similarly once at the forefront of the nation's development and flourishment, but for different reasons. Princeton's rise to fame began during the American Revolution as the site of the first major victory against the British, arguably the turning point of the war. Then, in 1783, Congress chose to move the capital of the colonies due to unrest from unpaid American soldiers. Princeton offered the ideal location as a midpoint between Philadelphia and New York City, with the largest building in the world, Nassau Hall, to serve as the meeting place for the Continental Congress [11]. Interestingly, the choice for where to move the capital was between Trenton and Princeton, but Princeton was ultimately chosen [12]. Though the arrangement lasted only a few months, Princeton's place in history was set in stone. Throughout the years, Princeton grew its reputation as the College of New Jersey, now known as Princeton University, expanded its academic offerings, and became recognized as a leader in its growing fields. The history and location attracted top students to the college, as did its unique features, like its preceptorial and honor systems implemented by the College's president, Woodrow

J Pub Health Issue Pract

Volume 3. 2019. 146
Wilson, in the early 1900s [11]. Today, Princeton University is one of the eight Ivy League colleges, widely regarded as one of the best and most selective research universities in the U.S. Notable alumni and faculty abound, including Nobel Prize winners, former presidents, and Fortune 500 company founders [13]. Princeton has attracted highly-educated and accomplished individuals for centuries, shaping it into what it is today.

The stark differences in the two cities' histories and present-day situations play a huge role in how the social determinants of health analyzed in this report have manifested themselves differently in Princeton and Trenton, leading to the substantial life expectancy gap of 14 years.

\section{Race}

When analyzing the causes of the life expectancy gap between Trenton and Princeton, differences in the racial compositions of the towns must be accounted for. In Trenton, $47.53 \%$ of the population is black while $32.24 \%$ is white. These numbers are drastically different in Princeton, where $51.21 \%$ of the population is white and only $3.35 \%$ is black. Notably, $41.25 \%$ of Princeton's population is Asian [14]. It is evident that a wealth gap with historical roots exists between whites and minority groups in America that cannot simply be overcome through income equality [15].

The overall median household income in Trenton is $\$ 45,326$, while in Princeton, it is $\$ 182,649$. An African American that resides in Trenton still makes less than a resident that is white $(\$ 40,313$ for African Americans vs. $\$ 52,650$ for whites). While African Americans living in Princeton are economically more advantaged than those in Trenton, a large income gap is present between African Americans and whites in Princeton; the African American population in Princeton holds a median household income of $\$ 82,904$ compared to $\$ 165,023$ for whites in Princeton [16]. Likewise, $18.33 \%$ of Trenton families compared to $2.29 \%$ of Princeton's families live below the poverty line [14]. This data is not due to chance; racial advantages present in American society need to be accounted for.

These racial differences were studied by American sociologist Dalton Conley, the Henry Putnam University Professor of Sociology at Princeton University. He found that whites living in the U.S. are significantly advantaged in health and longevity over other races, regardless of income or education level. As black Americans have overall worse health than whites despite economic or educational differences, other factors must be accounted for. Conley suggests that dealing with racism and stigma in everyday life leads to feelings of inadequacy and low worth, which causes this group stress that wears down their bodies. Additionally, he found that people with high incomes and thus higher socioeconomic status live longer than those who do not. Populations with higher socioeconomic status smoke less often, consume healthier foods, and exercise more often because they have the information and ability to make these healthy choices [15].

\section{Education}

Conley (15) conducted an additional study that analyzed educational abilities in America between blacks and white. After he factored out differences in class, he found that African Americans had a greater chance of graduating from high school, were $44 \%$ less likely to be held back a grade, and were equally likely to be suspended or expelled from school as white students. This shows that differences in education rates between Trenton and Princeton are not attributed to race.

Education leads to empowerment. Those who are educated, whether it be about politics, medicine, or history, have an increased ability to contribute to society and an opportunity to enhance their knowledge and skills. There are more job opportunities and there is an increased respect for those who are educated. More importantly, education allows people to reduce the inequalities that may be against their 
favor, such as poverty. Those who come from an unfortunate background can give themselves better job and life opportunities if they pursue an education and a college degree.

The difference between the quality of education between Princeton and Trenton is clear when statistics like graduation rate and standardized test scores are examined. In our analysis, statistics from Princeton High School and Trenton Central High School: Main Campus were compared. The differences in the amount of people who have high school degrees in Princeton and Trenton can be attributed to the graduation and dropout rates in each town. In 2017, Princeton High School had a graduation rate of $97.45 \%$ whereas Trenton Central High School: Main Campus had a graduation rate of $81.73 \%$. This is consistent with the fact that fewer people living in Trenton have high school degrees and even fewer college degrees. In reference to dropout rates at the two high schools, Trenton Central High School: Main Campus has a higher dropout rate at $1.7 \%$, whereas Princeton High School's rate is only $0.2 \%$. These rates are consistent with and help to support the trend that Trenton does not have as many people educated on the higher level compared to the amount of people in Princeton who have received higher levels of education [17-18].

According to the U.S. Census Bureau, $71.9 \%$ of the population of Trenton have a high school degree and $11.9 \%$ of the population have a bachelor's degree or higher. These percentages are very low compared to those of Princeton. In Princeton, 95.7\% of the population have a high school degree and $78.7 \%$ of the population have a bachelor's degree or higher. Having a bachelor's degree allows people to pursue white-collar jobs, such as doctors, nurses, business professionals, etc. These jobs generally pay more and provide more benefits. Even just having a high school degree provides so many more opportunities compared to not having any type of educational degree at all. From these statistics, there is vast difference in the amount of people who have bachelor's degrees or higher between Trenton and Princeton. Only $11.9 \%$ of the Trenton population have graduated and earned a college degree or a higher degree [19]. It can be inferred that most people residing in Trenton probably have lower incomes than those in Princeton. This means that these people cannot afford to go to college and pursue a college degree, therefore, they will not have as high paying jobs as people who have college degrees.

When looking at standardized test scores from 2016, there was a lack of information on SAT and ACT scores for Trenton. Therefore, we decided to exclude these standardized test scores and only based our analysis on the high schools' PSAT performance. In Princeton, the PSAT school mean was 1176 and in Trenton the PSAT school mean was 802. Trenton's PSAT school mean was lower than that of New Jersey's (950) [17-18]. This difference in PSAT test scores can be attributed to the lack of resources needed to prepare for these standardized tests. The people residing in Trenton may not have the books, tutoring, and practice tests that are used to help students prepare for the standardized tests. These test scores could help to explain why the graduation rate is lower for Trenton Central High School: Main Campus compared to the graduation rate of Princeton High School. Standardized tests are used to determine a student's college preparedness, therefore, if the students are performing poorly on these tests, then this could indicate that the students at Trenton Central High School: Main Campus are not prepared to go to college.

The school climate could also heavily impact how students are performing, which ultimately affects their chances of earning high school degrees. If classrooms are distracting because students are not being studious, then students are not performing to their best potentials. If students are consistently being suspended, other students are being distracted by the unnecessary drama. The school suspension rates vary greatly between Princeton High School and Trenton Central High School: Main Campus. Princeton High School has a suspension rate of $1.2 \%$ and Trenton Central High School:
Main Campus has a suspension rate of $14.4 \%$. Clearly, Trenton Central High School: Main Campus has a much higher suspension rate [17-18]. This is due to many factors other than poor conduct and misbehavior. Students can be suspended for failing to attend class. Students may be missing class because they have issues happening in their homes or are working a job in order to earn more money to support their families.

\section{Employment}

There is a large difference in the types of jobs that are most prevalent in Princeton and Trenton. The top three types of jobs in Princeton are in the fields of education, training, and library $(22.9 \%)$, management (13.4\%) and administrative services (7.7\%). In comparison, $15.1 \%$ of the working population in Trenton have jobs in administrative services, $11.8 \%$ have jobs in the cleaning and maintenance field, while $10.4 \%$ have jobs in food and service [19]. Generally, jobs in education, management, and administration are higher paying than jobs in the field of cleaning and food and service. As has been continuously stated, it can be inferred that these findings are due to the fact that fewer people have bachelor's degrees or higher in Trenton. One cause leads to another. Because fewer people have bachelor's degrees, then it makes sense that most people residing in Trenton do not have white collar jobs, which require a higher level of education.

Unemployment rates are also another contributing factor to increased rates of poverty, which ultimately leads to a lower quality of life, and therefore, a lower life expectancy as well. There are much higher unemployment rates for the population aged 16 and up in Trenton in comparison to the unemployment rates in the same population type in Princeton. According to DATAUSA, (20) there is a $15.17 \%$ unemployment rate in Trenton and a $4.37 \%$ unemployment rate in Princeton. Larger percentages of the population being unemployed means that larger percentages of the population are falling below the poverty line. This greatly affects people's lifestyle choices. People cannot afford to be educated or eat healthy, nutritious foods which greatly affects their life expectancy.

Careers may fill pockets, but such is not the case for individuals working blue- and pink-collar jobs who lack the post-secondary education necessary to attain lucrative careers. According to data gathered from the Trenton Health Team [16], Princeton has a median household income of $\$ 182,649$, four times Trenton's median household income of $\$ 45,326$. Even the richest neighborhood in Trenton, Census Tract 0013 in the northwestern portion of Trenton, was poorer than Princeton's poorest neighborhood, Census Tract 0040 in the center of Princeton. These neighborhoods have median household incomes of $\$ 61,060$ and $\$ 77,984$, respectively. The gap between the two towns is starkest when comparing Trenton's poorest neighborhood, Census Tract 0011.02, to Princeton's richest neighborhood, Census Tract 0042.03. In the latter, the average family makes $\$ 200,278$, whereas the former makes only $\$ 18,138$. That leaves a gap of $\$ 182,140$, and this gap alone is over ten times what families in that area of Trenton make annually. Whether the cause or effect of such income disparities, the cost of housing is directly proportional to the median household income. In Trenton, the median property value from 2015 was $\$ 107,200$. This is a little less than three times the median household, affordable for only $37.5 \%$ of people to fully own. In contrast, the median property value in 2015 was $\$ 780,300$ in Princeton, where 58.8\% own their homes [19].

\section{Environment}

The environment that one lives in is a large determinant of health. Many health conditions, including respiratory infections, asthma, lead poisoning, injuries, and mental health, are associated with poor housing conditions [22]. This is applicable to the differing situations in Trenton and Princeton. The age-adjusted Emergency Room (ER) rate due to adult asthma in Trenton from 2012-2014 was 141.1 ER 
visits per 10,000 population. In Princeton, this rate was dramatically less, at 13.2 ER visits per 10,000. Likewise, the same rate due to pediatric asthma was 246.4 ER visits per 10,000 in Trenton compared to 39.4 in Princeton [23]. Additionally, high blood lead levels adversely affect intelligence, behavior, and development [22]. In Trenton, lead poisoning cases are significantly higher than in Princeton. The New Jersey Department of Health [24] reported childhood lead poisoning prevalence in 2016 in large municipalities in New Jersey. Using Census data, they calculated the number of children in each area and tested a percent of this population for Blood Lead Level $(\mu \mathrm{g} / \mathrm{dL})$, categories ranging from $<5,5-9,10-14$, $15-19,20-44$, and $>45$. In Trenton, a total of 3,307 children out of the 3,525 children tested for $<5 \mu \mathrm{g} / \mathrm{dL}$ of lead in their blood, which is considered safe [25]. However, 218 children tested above $5 \mu \mathrm{g} / \mathrm{dL}$ out of this group, equivalent to $6.18 \%$ of the population of children in Trenton. Trenton ranks 6th among large municipalities (population of $>35,000)$ for number of children $(<6$ years of age) reported with elevated blood lead levels.

Because Princeton does not classify as a large municipality, it was not included in this data. However, the two towns can be compared by noting the differences in the number of Elevated Blood Lead Level (EBLL) cases reported in the two towns. The report also stated that New Jersey law (N.J.S.A. § 24:14A-6) requires local health departments to investigate all reported cases of EBLL and to order the abatement of all lead hazards identified in the course of the investigation. In the same 2016 report, the New Jersey Department of Health [24] published that the Princeton Health Department had one environmental case referred to their health department, which did not end up requiring investigation. In Trenton, 23 cases were reported, of which 11 required further investigation. According to Princeton Health Department Assistant Administrator/Public Health Officer, Jeffrey Grosser, water and sanitation efforts are comparable between the two towns (Grosser, Jeffrey. Interviewed by three of this report authors on 2018 Apr 23). Keeping this in mind, one can infer that the issue lies in a lack of maintenance and service upkeep in lower income housing.

When maintenance and service are not routinely performed, living conditions become more and more unsafe, and accidents are more likely to occur. This is evident in the crude rates of unintentional injuries out of 100,000 population between the two towns: 41.6 deaths in Trenton compared to 22.4 deaths in Princeton(26).

One sociological study [27] demonstrates a positive association between healthy living conditions and environments and a healthy lifestyle. A sample of families was randomly assigned to move to a low-poverty area, and the control group was able to move to wherever they wanted, usually a wealthier area. The experiment was named "Moving to Opportunity" (MTO). Families in the control group reported experiencing less stress from violence and other factors. In addition, these families generally felt healthier and happier than in their previous living arrangements. Most notably, children in the control group showed dramatic results, where children with higher socioeconomic status, regardless of race, rise above their counterparts as a result of their environments. This not only demonstrates the effects of poverty on families but also shows how the opportunity to be happy and healthy in America is unequally distributed amongst Americans depending on their surrounding environment. The environment that Americans live in is usually determined by their socioeconomic status, as wealthier individuals live amongst each other and similarly with lower class populations. As with education, being surrounded by motivated students increases productivity and success amongst individuals who would not have done so in other circumstances [15]. Likewise, being surrounded by a healthy environment leads to feelings of higher worth despite socioeconomic status. Thus, those who live in Trenton may experience lower health due to this cause.
Land density is a contributing factor to the quality of the environment one lives in. The U.S. Census Bureau [19] found that Trenton had 84,056 residents as of 2016 distributed across 7.65 square miles of land [28]. This puts Trenton's population density at 10,988 people per square mile of land. Because so much space is needed to house and sustain such a dense population, there is little room for parks. Just over 180 acres of green space is reserved as parks and can be used by the public [29]. In terms of food, there are around 20 places listed under "grocery stores" within Trenton's borders on Google Maps, including grocery stores, markets, supermarkets, and delis, not including corner stores. If Trenton's residents used only these 20 grocery stores, each store would serve approximately 4,203 people. There are 12 fast food restaurants, or about 1.57 per square mile of land [30].

Princeton Borough and Princeton Township, on the other hand, had a combined 31,249 residents in 2016 [19], distributed across 17.93 square miles of land [28]. Princeton thus had a population density of 1,742 people per square mile. Much of Princeton's area is dedicated to reservations and other parks. One park alone, Institute Woods, has 589 acres of green space open to the public, triple the combined area of every park in Trenton. This is just one park of many that contain several hundred acres of green space. Google Maps [31] lists 18 places as "grocery stores" within Princeton's borders, including grocery stores, markets, supermarkets, and several other types of food stores. When narrowed down to just grocery stores, markets, and supermarkets, 14 stores remained. It is important to note that of these 14, 5 contained the words "whole," "organic," or "gourmet" in their names or descriptions, whereas Trenton's stores had none of these. If Princeton's residents used only these 14 grocery stores, each store would serve 2,232 people. There are 14 fast food restaurants, and 13 when excluding one restaurant with very expensive options. This ratio comes out to be about 0.73 fast food restaurants per square mile of land, a fast food density less than half that of Trenton. In simple terms, for every two fast food restaurants in Trenton, there is one in Princeton.

The quality of the environment between the two towns also depends on public safety. As a population that feels unsafe would be less inclined to exercise outside or bring their child to the park, health relates to how safe the residents of a town feel when they leave the house. The FBI [32] recorded data in 2015 on reported crime in U.S. cities. The following numbers reflect incidents occurring relative to Trenton and Princeton populations at the time, which were 83,662 and 30,447 , respectively. For comparative purposes, the numbers have been converted into incidence rate per 10,000 population, with the raw data written in parentheses beside the rate. In 2015, there were 121.7 reports of violent crime in Trenton per 10,000 people $(1,018$ reports) compared to 4.3 per 10,000 people (13 reports) in Princeton. Twoof every 10,000 Trentonians were victims of non-negligent manslaughter or murder (17 murders), whereas there were no reports of murder in Princeton. There were 5.7 reports of rape per 10,000 population in Trenton (48 reported rapes), and 0.33 reports of rape per 10,000 population in Princeton (1 reported rape). 48.1 robberies occurred per 10,000 Trentonians (402 robberies), and 0.66 robberies occurred per 10,000 Princetonians (2 robberies). There were 65.9 aggravated assaults in Trenton per 10,000 people (551 incidents), compared to 3.3 aggravated assaults in Princeton per 10,000 people (10 incidents). This data about public safety shows that there is an increased chance that Trenton residents would feel unsafe going outside. One can gather from this data that the life expectancy gap disparity can be attributed to this and the other previously mentioned environmental factors.

\section{Chronic Diseases and Access to Healthcare}

Chronic diseases and conditions, such as obesity, heart diseases, and diabetes, are directly linked to a decrease in not only length of life, but quality of life, as well. When Trenton's citizens need medical 
care for conditions such as chronic diseases, they can go to four hospitals or around 20 clinics of different specialties. Still, $23.1 \%$ of people under 65 years old are uninsured, thus unable to utilize many of these resources. When Princeton residents need medical care, there are three general and specialty hospitals and 12 medical clinics within the town, as well as Princeton and Penn Medicine facilities just outside Princeton's borders. These are easily accessible, as only $3.7 \%$ of Princetonians under 65 years old are uninsured [19]. The uninsured are at many disadvantages when it comes to healthcare because they are unable to receive preventative care, thus being hospitalized and dying from avoidable conditions more often than the insured. According to the Henry J. Kaiser Family Foundation [33], around $20 \%$ of uninsured adults did not seek out necessary medical care because they could not afford it, causing worsened conditions and a greater likelihood of death. When emergencies occur, medical bills can pile up quickly, putting those who are already economically strapped into further debt [34].

Heart disease is the leading cause of death in both Princeton and Trenton. In 2016, there were 146 deaths due to heart disease in the Trenton population of 84,056 people. In comparison, there were 48 deaths out of 31,249 people in Princeton. This means that the death rates are 173.7 deaths per 100,000 population in Trenton and 153.6 deaths per 100,000 population in Princeton. These are relatively similar rates, Trenton's being slightly higher. The same is true when comparing death rates due to stroke between the two cities. In Princeton, the death rate due to stroke was 22.4 deaths per 100,000 population ( 7 deaths out of 31,249 people). In Trenton, the death rate was 35.7 deaths out of 100,000 population (30 deaths out of 84,056 people). Again, these rates do not differ by much. However, when comparing the death rates due to diabetes in both of the cities, large differences can be seen. In 2016, there were 30 people out of 84,056 people who died because of diabetes in Trenton. This means the death rate was 35.7 deaths per 100,00 population. In Princeton, only 2 people out of 31,249 people died due to diabetes for a death rate of 6.4 deaths per 100,000 population [26]. Clearly, the death rate due to diabetes is much higher in Trenton than it is in Princeton. When looking at these three chronic diseases, Trenton's death rates due to heart disease, stroke, and diabetes are all higher than the death rates in Princeton. There is a multitude of reasons as to why the death rates are higher in Trenton than they are in Princeton. Obesity, lack of exercise, and lack of fresh food options are examples.

Obesity is multifactorial, which in turn can cause the development of chronic disease. Lack of exercise, a risk factor for chronic diseases, is higher in Trenton than in Princeton. The World Health Organization [35] recommends that children get 60 minutes of exercise daily and adults get 150 minutes of exercise per week. Reasons why residents may not get the recommended amount of exercise include lack of resources and areas to be physically active, unsafe neighborhoods where high crime rates exist, and poverty. We also discussed work wellness programs in place at Grosser's workplace; paid gym memberships are offered to employees with higher income jobs. These employees are able to exercise during their lunch breaks, therefore, making it easier for workers to exercise daily and decrease their risk of becoming obese. Crime rates are significantly higher in Trenton than they are in Princeton, as previously stated. In Trenton, there are also fewer recreational centers and parks where people can engage in physical activities and exercise.

A big contributor to Trenton's high obesity rates could be the high density of fast food restaurants and the lack of grocery stores and fresh food options. There is a quasi-food desert present in Trenton, meaning that the scarce food options that are available are not necessarily nutritious and healthy. Further, the average number of cars for Princeton is two cars per household, whereas in Trenton, it is one car per household [20]. This means that there is less accessibility to fresh food options for residents in Trenton because they do not necessarily have the transportation available to them. Poor diet and lack of exercise are major risk factors for many chronic diseases as well as contributors to lower life expectancy. All these factors lead to increased rates of obesity, which is a major risk factor for the development of multiple chronic diseases, such as cardiovascular disease, stroke, and diabetes. Increased body fat percentages increase the plaque buildup in the arteries causing the heart to weaken which can lead to cardiovascular disease as well as stroke [36]. In addition, increased body fat, especially around the waistline, affects how pancreatic cells function and prevents the cells from using insulin properly, leading to elevated blood sugar levels in the body [37]. This is a direct cause of diabetes. Clearly, the onset of a chronic disease is multifactorial. Multiple variables, like socioeconomic status, genetic factors, education, and available resources affect whether an individual develops a chronic disease [38].

Healthcare and insurance inequalities can be observed by analyzing ER and hospitalization rates of diseases between the two towns. The age-adjusted ER rate per 10,000 population due to diabetes in Princeton is much lower than that in Trenton (3.3 vs. 64.6). Due to long-term complications of diabetes, the rate in Princeton is 2.8; in Trenton, the rate is 23.4. Additionally, ER rates due to hypertension in Trenton is 60.4, while it is 10.9 in Princeton. Trenton's hospitalization rate due to heart failure is 57.4; Princeton's is 20.6 [23]. Trenton ER and hospitalization rates are higher due to a general lack of health insurance in this population; easily preventable and treatable diseases are more likely to manifest into conditions that need urgent medical attention in this population.

The second leading cause of death in both Princeton and Trenton is cancer. In 2016, NJSHAD reported that 141 out of 84,056 people died of cancer in Trenton and 31 out of 31,249 people died of cancer in Princeton. For comparative purpose, this equates to a death rate of 167.7 per 100,000 population in Trenton, and 99.2 per 100,000 population in Princeton [26]. While the causes of cancer vary widely from person to person, risk factors can be split into two groups: those that can be controlled and those that cannot. Age and family history, for example, are two risk factors that cannot be controlled and would affect both Trenton and Princeton equally. Therefore, the differences between cancer death rates in the two cities are likely due to factors that can be prevented and controlled.

Lifestyle factors play a role, as diet and activity level can protect against or predispose someone to cancer development. Princeton's superior resources in terms of healthy food options and area to exercise freely and safely make it much easier for these residents to engage in healthy lifestyle choices. Even when Trentonians are aware of the causes of chronic diseases like cancer, taking the necessary steps to protect themselves from it is often not possible with violence or a lack of access to affordable organic foods and green space.

Environmental contaminants also act as carcinogens. These contaminants can reveal themselves in both the workplace, homes, and surrounding environment [39]. In terms of occupational cancer, Trenton has a higher percentage of the population working in jobs that could expose workers to carcinogens. While a majority of Princeton's population occupy the fields of education, management, and administrative services, of which the working environment is generally safe and free of carcinogens, the majority of Trenton's population is involved in production/transportation and cleaning/ maintenance [20]. Production and transportation in Trenton include metal production, truck drivers, and ceramic production. Metal production exposes workers to aromatic amines, driving exposes works to Diesel engine exhaust, and ceramic production exposes workers to cobalt, all of which are carcinogens. Cleaning and maintenance often involve fumes and other chemicals that can cause cancer, including benzene in detergents [40]. With housing, poor maintenance and safety in housing lead to the high rates of lead poisoning in Trenton [23], likely from pipes and paint, which can cause lung and stomach cancer, among others [41]. 
Immunosuppression and prior infection are exposures to cancer, as well [39]. According to NJSHAD's [26] most common causes of death in Trenton and Princeton, both cities experienced deaths due to kidney disease, pneumonitis, chronic lower respiratory diseases, and influenza and pneumonia in 2016, all of which cause a weakened immune system [42]. For each of these, the crude rates of death in a 100,000 population were higher for Trenton except for pneumonitis due to liquids and solids, which was higher in Princeton. Trenton also reported numerous other diseases that can lead to immunosuppression, including liver disease, HIV, viral hepatitis, and septicemia, that were not reported as a common cause of death in Princeton [26]. These conditions are once again conditions of the poor and uninsured who cannot get the treatment to stop the diseases in their early stages. Having no insurance also means that these individuals are less likely to get yearly check-ups to detect cancer in its early stages when it is most treatable, leading to higher rates of death by cancer.

It is important to note that there are evident differences in the major causes of death between Trenton and Princeton; these can likely be attributed to an increase of certain risk factors for more uncommon causes in one town versus the other. In Trenton, for example, septicemia is a substantial cause of death, taking 3.3\% of residents lives (21 individuals) in 2016, translating to a crude rate of 25 individuals per 100,000. The condition, however, fails to be listed as one of the top 24 causes of death in Princeton [26]. This is troublesome as septicemia is widely preventable. All infections can lead to sepsis, but this is easily avoidable if care is readily available and the pre-existing illness is promptly treated. It is easier for an infection to lead to sepsis if an individual has a weakened immune system due to HIV/AIDS, cancer, or cancer treatment. It is also more likely for septicemia to develop in those who live with chronic diseases such as diabetes [43]. In Trenton, HIV/AIDS, cancer, and diabetes affect residents at higher rates than in Princeton. (26) As aforementioned, the low-income population in Trenton does not receive the same high-quality healthcare that the residents of Princeton do, as more of the population is uninsured in Trenton [19]. This difference in healthcare combined with the increased presence of risk factors in Trenton residents leads to a higher rate of death due to septicemia when compared to Princeton.

\section{Limitations of this Crtical Report}

This report aimed to critically discuss the relevant gap in life expectancy between Trenton and Princeton under the basis of the social determinants of health. Technically, the data reported for Princeton's life expectancy was for the zip code 08550, or Princeton Junction, a town associated with West Windsor Township just southeast of Princeton. However, a representative at the RWJF estimated that the life expectancy would be roughly the same for Princeton. Still, in order to get the most accurate comparison between the two cities, we found data on the average age at death from NCHS's 113 selected causes of death for all Trenton or Princeton residents in 2016, regardless of sex, race, and place of occurrence.

Additionally, the report was based on secondary data that is available to the public. While the sources were reliable, collection methods could have varied depending on the organization that collected the primary data, thus possibly contributing to bias in the comparison. Other factors (e.g. lead contamination) that also have been associated with life expectancy were not accessed due to insufficient data available, so the information presented here is not comprehensive of all variables.

Google Maps was utilized to get a rough estimate of the number of fast food restaurants, grocery stores, hospitals, and parks in the two cities. This is likely the service that residents of Princeton and Trenton use to locate these places, and thus show basic availability and quality of each of the categories. However, the number of facilities found is only what Google grouped into the categories "fast food," "grocery stores," "hospitals," "clinics," and "parks." If a fast food restaurant was listed under "restaurant" instead, for example, it would not be included in the final count. Some of the facilities Google Maps listed were located outside of the cities and not counted either, and some were subjectively excluded because they did not seem to fit the category.

Another limitation is that crude death rates were used in the chronic disease section because the data to calculate age-adjusted rates was not available for Princeton. Age-adjusted rates would have helped to differentiate the deaths due to environmental factors from those due to age. Lastly, this is a descriptive critical report and no causality can be assumed from the conclusions drawn.

\section{Conclusion}

The U.S. is a well-developed country with some of the most innovative medical advancements in the world. However, health disparities still present a major public health challenge that manifests itself in residents who live just 12 miles apart, as seen in Trenton and Princeton, New Jersey.

The life-expectancy gap will continue to grow between these towns unless political action is taken. There cannot be a disconnect between the government and the community; it is necessary for government officials to listen to individual voices from the areas that they are impacting, whose lives depend on the actions they do or do not take. Any public policies implemented should be a collaboration between the public sector and private sector of Trenton in order to reach all consumers while still having the resources and funding available from the government to initiate the policies.

In addition to creating and instituting public health policies that would focus on improving social determinants in Trenton, it is vital to follow up on what progress is being made and to continue to make adjustments and improvements. The community would likely be more receptive to change if they are able to trust that the companies involved are really in it for the wellbeing of the community as opposed to simply the economics.

This public health crisis is unacceptable and preventable. Although the U.S. is a well-developed country, the high-quality healthcare that is available is not equally distributed among the population and is virtually unavailable to the populations that need it most. In theory, each individual in the United States should have the opportunity to choose to be healthy, but this is not an easy option for residents in lowincome areas like Trenton. In order for this to truly be achieved, large and local companies alike need to recognize the long-term benefits of public health improvements, facilitated by short-term incentives from higher and more resourceful councils. In addition, populations need to be not only educated on how to make healthy decisions but also motivated and incentivized to execute the behavioral shifts that are necessary to actually accomplish a healthy lifestyle.

The United States was founded on equality, and it is time for this sentiment to be actively applied to the population through governmental efforts and collaboration with communities in places like Trenton. By targeting the inequities in social determinants between the two cities, a chain of cause-and-effect will begin. The outcomes from one initial action can effect multiple positive changes, and each of those can act as a catalyst for even more change. Though it is impossible to eliminate people's conceptions of inequities in our society, progress can be made to lessen the life expectancy gap between Princeton and Trenton, as well as the thousands of similar cities that exist in America.

Conflict of interest: The authors have declare no conflict of interest.

\section{References}

1. World Health Organization [Internet]. Geneva $(\mathrm{CH})$ : World Health Organization; c2018. Life expectancy at birth; 2006 [cited 2018 May 1]; [about 2 screens]. 
2. The World Bank (2018) Washington, DC: World Bank Group; c2018. Life expectancy at birth, total (years); 2017.

3. Kochanek KD, Murphy SL, Xu JQ, Arias E (2016) Mortality in the United States. NCHS data brief 293.

4. United Nations Department of Economic and Social Affairs (2018). United Nations; c2018. Publications.

5. The World Bank In Africa (2018). Washington, DC: World Bank Group Overview.

6. Marmot M, Bell R (2016) Social inequalities in health: a proper concern of epidemiology. Ann Epidemiol 26: 3.

7. Healthy People (2018). Washington, DC: Office of Disease Prevention and Health Promotion; c2018. Social determinants of health.

8. Culture of Health (2018) Princeton (NJ): Robert Wood Johnson Foundation; c2018. Tackling life expectancy gaps in New Jersey; 2016 November 9 [cited 2018 April 29]; [about 10 screens].

9. New Jersey State Health Assessment Data (2018) Trenton (NJ): New Jersey Department of Health; c2017. Query results for New Jersey mortality data: 2000-2015 - Average age at death; 2018 March 26 [cited 2018 April 29]; [about 2 screens].

10. Richman S (2011) Reconsidering Trenton: the small city in the post-industrial age. Jefferson: McFarland \& Company; 2011.

11. Gambee R. Princeton. New York: W. W. Norton \& Company; 1987.

12. Princeton University (2015) Princeton (NJ): Princeton University; c2018. July 4 is milestone in America's - and Princeton's - history; 2015 July 2 [cited 2018 April 29]; [about 20 screens].

13. Princeton University (2018) Princeton: Princeton University; 2018 [cited 2018 May 1].

14. Trenton Health Team (2018) Trenton (NJ): Trenton Health Team; c2018. Health indicators; 2018 January [cited 29 April 2018]; [about 7 screens].

15. Conley D (2015) You may ask yourself: An introduction to thinking like a sociologist. Edition 4. New York: W. W. Norton \& Company.

16. Trenton Health Team (2018) Trenton (NJ): Trenton Health Team; c2018. Median household income; 2018 January [cited 29 April 2018]; [about 7 screens].

17. NJ School Performance Report (2015-2016) Princeton (NJ): State of New Jersey Department of Education; c2015. 20152016 School performance reports; [2015-2016].

18. NJ School Performance Report (2015-2016) Princeton (NJ): State of New Jersey. Department of Education; c2015. 20152016 School performance reports; [2015-2016]

19. United States Census Bureau (2018) Washington, DC: U.S. Department of Commerce; c2018. Trenton city, New Jersey; Princeton, New Jersey; [2010-2017].

20. DATAUSA (2018) [place unknown]: Datawheel; c2018. Princeton, NJ \& Trenton, NJ;

21. Trenton Health Team (2018) Trenton (NJ): Trenton Health Team; c2018. Population 16+: Unemployed.

22. Krieger J, Higgins D (2002) Housing and health: time again for public health action. Am. J. Pub Health 92: 10.

23. Trenton Health Team (2018) Trenton (NJ): Trenton Health Team; c2018. Hospitalization and ER data.

24. Childhood Lead Exposure in New Jersey: Annual Report (2018) Trenton (NJ): New Jersey Department of Health; c2016. [date unknown] [cited 2018 May 2]; [about 76 screens].
25. Centers for Disease Control and Prevention (2018) Atlanta: U.S. Department of Health and Human Services; c2018. CDC's childhood lead poisoning prevention program; 2017 May 17 [cited 2018 May 2]; [about 2 screens].

26. New Jersey State Health Assessment Data (2017) Trenton (NJ): New Jersey Department of Health; c2017. Query results for New Jersey mortality data: 2000-2015 - Crude rates (deaths per 100,000 population) for municipalities; 2018 March 26 [cited 2018 May 1]; [about 2 screens].

27. Moving to Opportunity for Fair Housing Demonstration Program: Final Impacts Evaluation (2011) New York (NY): U.S. National Bureau of Economic Research; 2011 November [cited 2018 April 29]; [about 500 screens].

28. United States Census Bureau (2018) Washington, DC: United States Census Bureau; c2018. County subdivisions: New Jersey - 2010 Census gazetteer files; 2010 [cited 2018 May 1]; [about 12 screens].

29. City of Trenton, NJ (2018) Trenton (NJ): City of Trenton; c2010. City parks; [date unknown] [cited 2018 April 29]; [about 4 screens].

30. Google Maps (2018) Mountain View (CA): Google LLC; c2018. Trenton, NJ; 2018 [cited 2018 May 2]; [about 1 screen].

31. Google Maps (2018) Mountain View (CA): Google LLC; c2018. Princeton, NJ; 2018 [cited 2018 May 2]; [about 1 screen].

32. Uniform Crime Reporting (2018) Washington DC; Federal Bureau of Investigation; c2018. Table 8: New Jersey offenses known to law enforcement; 2015 [cited 2018 April 29]; [about 30 screens].

33. Kaiser Family Foundation (2018) Menlo Park (CA): Kaiser Family Foundation; c2018. Key facts about the uninsured population; 2017 November 29 [cited 2018 April 29]; [about 35 screens].

34. Centers for Disease Control and Prevention (2017) Atlanta (GA): U.S. Department of Health \& Human Services; c2017. The medically uninsured; 2017 September 15 [cited 2018 April 29]; [about 3 screens].

35. World Health Organization (2010) Geneva (CH): World Health Organization; c2018. Global recommendations on physical activity for health; 2010 [cited 2018 April 29]; [about 60 screens].

36. American Heart Association (2017) Dallas (TX): American Heart Association; c2018. Causes of heart failure; 2017 May 8 [cited 2018 April 29]; [about 3 screens].

37. Sizer FS, Whitney EN (2016) Nutrition concepts and controversies. 14th ed. Boston (MA): Cengage Learning.

38. Cleveland Clinic (2013) Cleveland (OH): Cleveland Clinic; c2018. Lifestyle choices: root causes of chronic diseases; 2013 January 14 [cited 2018 April 29]; [about 15 screens].

39. Sloan FA, Gelband H (2007) Cancer causes and risk factors and the elements of cancer control. Nat Acad of Sci [Internet]. 2007 [cited 2018 April 29]; [about 50pp.].

40. Canadian Centre for Occupational Health and Safety (2018) Hamilton (ON): Government of Canada; c2018. Occupations or occupational groups associated with carcinogen exposures.

41. American Cancer Society (2014) American Cancer Society, Inc; c2018. Lead.

42. Mayo Clinic (2018) Rochester (MN): Mayo Foundation for Medical Education and Research.

43. MacGill, M. Medical News Today (2017) Brighton (UK): Healthline Media UK Ltd; c2018. Septicemia: know the facts. 